\title{
APLIKASI MODEL PEMBELAJARAN KOOPERATIF TIPE TGT (TEAMS-GAMES-TOURNAMENT) DALAM MENINGKATKAN MOTIVASI DAN HASIL BELAJAR BIOLOGI MATERI ANIMALIA SISWA KELAS X IPA SMA BINA INSAN MANDIRI NGANJUK TAHUN AJARAN 2018/2019"
}

\author{
Fadilah Rahmawati ${ }^{1}$, Budhi Utami ${ }^{2}$, Nurul Mufitdah ${ }^{1}$, dan Choirul $^{1}$ \\ ${ }^{1}$ SMA Bina Insan Mandiri \\ 2 Universitas Nusantara PGRI Kediri \\ Email: utamibudhi@gmail.com
}

\begin{abstract}
Abstrak
Tujuan penelitian tindakan kelas ini adalah untuk mengetahui aplikasi model pembelajaran kooperatif tipe TGT(Teams Games Tournamant) yang dapat meningkatkan motivasi dan hasil belajar biologi siswa kelas X IPA SMA Bina Insan Mandiri Nganjuk.Penelitian ini akan di lakukan melalui proses pengkajian berdaur, yang terdiri dari empat tahap, yaitu tahap merencanakan (planning), melakukan tindakan (action), mengamati (observation), dan melakukan refleksi (reflection). Hasil penelitian menunjukkan bahwa: a) terjadi peningkatan motivasi belajar siswa berdasarkan peningkatan jumlah skor motivasi siswa dari 38,6\% menjadi $61,4 \%$, b) terjadi peningkatan hasil belajar siswa dari peningkatan jumlah siswa yang mampu mencapai nilai tuntas, baik pada siklusl danllyang mengalami kenaikan dari 26 siswa (76,5\%) menjadi 32 siswa atau 85,2\%. Dari hasil ini dapat disimpulkan bahwa penerapan model pembelajarankooperatif tipe TGT (teams games tournament) mampu meningkatkan motivasi dan hasil belajar biologi untuk materi Animalia pada siswa kelas X IPA SMA Bina Insan Mandiri Nganjuk.
\end{abstract}

Kata kunci- Model kooperatif TGT, Hasil, Motivasi belajar

\section{PENDAHULUAN}

Dalam upaya meningkatkan mutu pendidikan, mutu guru merupakan salah satu komponen yang mempunyai peran sangat penting. Salah satu upaya untuk meningkatkan mutu pendidikan di sekolah adalah dengan cara perbaikan proses belajar mengajar atau pembelajaran [1]. Guru sebagai pendidik yang menduduki posisi strategis dalam pengembangan sumber daya manusia, dituntut untuk terus mengikuti perkembangan konsep-konsep baru dalam dunia pendidikan.

Fenomena di lapangan selama ini menunjukkan bahwa dalam proses pembelajaran masih banyak permasalahan di dalamnya. Dari hasil pengamatan di kelas serta diskusi dengan guru, dalam proses belajar biologi di kelas X IPA SMA Bina Insan mandiri Nganjuk tahun ajaran 2018/2019, dengan jumlah 36 siswa putra serta ruangan yang kurang kondusif terdapat beberapa kelemahan yang mempengaruhi hasil belajar siswa berdasarkan hasil diagnosa. Kelemahan yang diperoleh dari hasil diagnosa diantaranya adalah: 1) partisipasi siswa/ fokus siswa terhadap pembelajaran rendah, 2) siswa kurang tertarik dengan cara guru menyampaikan materi (metode tidak bervariasi), dan 3) sebagian besar siswa kurang termotivasi untuk belajar. Dari hasil ini maka diperlukan suatu tindakan untuk meningkatkan terutama motivasi belajar siswa dalam pembelajaran Biologi.

Penelitian tindakan kelas dapat dilakukan dengan mengaplikasikan suatu model pembelajaran yang dapat membuat siswa menjadi aktif dan kreatif. Pembelajaran aktif merupakan suatu pembelajaran yang mengajak siswa untuk belajar secara aktif. Belajar aktif mendominasi aktivitas pembelajaran sehingga siswa secara aktif menggunakan potensi otak dalam hal menemukan ide pokok, memecahkan persoalan, atau mengaplikasikan apa yang baru dipelajari. Belajar aktif mengakibatkan siswa turut serta dalam proses pembelajaran sehingga siswa dapat menikmati suasana yang lebih menyenangkan dan hasil belajar dapat dimaksimalkan [2].

Metode yang dapat dikembangkan dari pembelajaran aktif juga harus mempertimbangkan keadaan siswa dan kemampuan siswa di kelas X IPA SMA Bina Insan Mandiri Nganjuk tahun ajaran 2018/2019 yang heterogen dengan kemampuan akademik tinggi, sedang, rendah dan latar belakang siswa yang berbeda sehingga memungkinkan siswa untuk berinteraksi dan saling mengkomunikasikan pengetahuan dalam proses pembelajaran. Melihat jumlah siswa yang besar, agar fokus siswa dan pertisipasi siswa dalam pembelajaran meningkat maka model pembelajaran kooperatif Teams-Games-Tournament (TGT) bisa menempatkan para siswa bekerja dalam kelompok-kelompok kecil untuk saling membantu satu sama lain dalam mempelajari materi pelajaran. TGT adalah pembelajaran kooperatif yang melibatkan kelompok, di dalamnya terdapat diskusi kelompok dan diakhiri suatu game/turnamen. Dalam TGT, siswa dibagi menjadi beberapa tim belajar 
Jurnal Biologi dan Pembelajarannya, Vol 7 No 1, April 2020. Pp: 11-14

e-ISSN: $2406-8659$

yang terdiri atas empat sampai enam orang yang berbeda-beda tingkat kemampuan dan latar belakang etniknya.

Dengan pembelajaran kooperatif Teams Games Tournament (TGT), para siswa diharapkan dapat saling membantu, berdiskusi dan berargumentasi untuk mengasah khasanah ilmu pengetahuan yang mereka kuasai dan menutup kesenjangan dalam pemahaman masing-masing. Model pembelajaran kooperatif Teams-GamesTournament (TGT) mempunyai kelebihan-kelebihan di antaranya: 1) Dengan waktu yang sedikit dapat menguasai materi secara mendalam, 2) Proses belajar mengajar berlangsung dengan keaktifan dari siswa, 3) Motivasi belajar lebih tinggi, 4)Mendidik siswa untuk berlatih bersosialisasi dengan orang lain, 4) Hasil belajar lebih baik, 5) Meningkatkan kebaikan budi, kepekaan dan toleransi [3].

\section{METODE PENELITIAN}

Metode yang digunakan dalam penelitian ini adalah penelitian tindakan kelas dengan model pembelajaran kooperatif tipe Teams-Games-Tournament (TGT). Bahan dan peralatan yang di butuhkan pada penelitian tindakan kelas ini adalah Perangkat pembelajaran, instrument penilaian, LCD Komputer dan hadiah.

Penelitian ini dilakukan melalui proses pengkajian berdaur yang terdiri dari empat tahap, yaitu tahap merencanakan (planning), melakukan tindakan (action), mengamati (observation), dan melakukan refleksi (reflection)

Penelitian ini menggunakan duateknik pengumpulan data yaitu teknik tes, atau teknik pengumpulan data dengan melakukan pretes dan pos tes sesuai materi yang di ambil saat penelitian baik pada siklus I dan II, dan non tes, yaitu teknik pengumpulan data dengan angket/ kuesioner yang dibagikan kepada siswa sebelum dan setelah penelitian ini dilaksanakan.

\section{HASIL DAN PEMBAHASAN}

Persepsi mahasiswa terhadap pembelajaran Kimia Dasar berbasis blended learning diukur pada 5 aspek, yaitu pemahaman, penerapan, fungsi, dan dampak. Hasil jawaban kuesioner mahasiswa dipersentasekan pada tiap aspek yang diukur. Pada aspek pemahaman terhadap pembelajaran blended learning diketahui bahwa 94,6 Hasil data pada pembelajaran biologi SMA kelas X semester I di SMA Bina Insan MandiriNganjuk tahun 2018/ 2019 pada materi animalia dengan Judul penilitian "Aplikasi model pembelajaran kooperatif tipe TGT (Team gamestournament) dalam meningkatkan motivasi dan hasil belajar biologi materi Animalia" hasilnya cukup memuaskan. Hasil angket motivasi siswa sebelum dan sesudah TGT menunjukkan bahwa siswa yang memiliki motivasi tinggi mengalami kenaikan dari $38,6 \%$ menjadi $61,4 \%$ yang artinya jumlah siswa yang motivasinya tinggi mengalami peningkatan. Berikut data rekapitulasi motivasi belajar siswa

\begin{tabular}{|c|l|c|c|c|c|c|}
\hline Skor & $\begin{array}{c}\text { Kriteria } \\
\text { motivasi }\end{array}$ & $\begin{array}{c}\text { Respon } \\
\text { pernyataan } \\
\text { isi angket }\end{array}$ & $\begin{array}{c}\text { Skor Pra } \\
\text { TGT }\end{array}$ & $\begin{array}{c}\text { Skor Pasca } \\
\text { TGT }\end{array}$ & $\begin{array}{c}\text { Prosentase } \\
\text { Pra TGT (\%) }\end{array}$ & $\begin{array}{c}\text { Prosentase } \\
\text { Pasca TGT } \\
\text { (\%) }\end{array}$ \\
\hline 5 & Sangat baik & SS & 362 & 576 & 38,6 & 61,4 \\
\hline 4 & Baik & S & 618 & 596 & 50,9 & 49,1 \\
\hline 3 & Sedang & RR & 543 & 408 & 57,1 & 42,9 \\
\hline 2 & Kurang baik & TS & 284 & 255 & 52,6 & 47,3 \\
\hline 1 & Rendah & STS & 78 & 134 & 36,7 & 63,2 \\
\hline
\end{tabular}

Tabel 1. Motivasi belajar siswa pra TGT dan pasca TGT (Nilai afektif)

Sedangkan data hasil belajar siswa, dengan pemberian pre-test sebelum TGT, dan post-test sesudah TGT adalah sebagai berikut:

\begin{tabular}{|c|c|c|}
\hline \multirow{2}{*}{ Siklus } & \multicolumn{2}{|c|}{$\begin{array}{c}\text { Prosentase Ketuntasan sesuai } \\
\text { KKM (\%) }\end{array}$} \\
\cline { 2 - 3 } & Pra-TGT & Paska-TGT \\
\hline Siklus I & 2,9 & 76,4 \\
\hline Siklus II & 17,6 & $85,2 \%$ \\
\hline
\end{tabular}

Tabel 2. Nilai hasil belajar siswa pra TGT dan pasca TGT (nilai kognitif) 
Jurnal Biologi dan Pembelajarannya, Vol 7 No 1, April 2020. Pp: 11-14

e-ISSN: $2406-8659$

Hal ini menunjukkan bahwa setelah pelaksanaan model pembelajaran kooperatif tipe TGT, hasil belajar siswa mengalami peningkatan baik pada siklus I maupun II. Pada siklus II jumlah siswa yang nilainya tuntas mengalami kenaikan mencapai $85,2 \%$.

\begin{tabular}{|l|c|c|c|c|c|c|c|c|}
\hline \multirow{2}{*}{ Parameter } & \multicolumn{4}{|c|}{ Siklus I (\%) } & \multicolumn{4}{c|}{ Siklus II (\%) } \\
\cline { 2 - 9 } & Kurang & Cukup & Baik & $\begin{array}{c}\text { Sangat } \\
\text { Baik }\end{array}$ & Kurang & Cukup & Baik & $\begin{array}{c}\text { Sangat } \\
\text { baik }\end{array}$ \\
\hline Minat & 0 & 0 & 80 & 20 & 0 & 0 & 60 & 40 \\
\hline Perhatian & 0 & 0 & 60 & 40 & 0 & 0 & 40 & 60 \\
\hline Partisipasi & 0 & 20 & 60 & 20 & 0 & 0 & 40 & 60 \\
\hline Presentasi & 0 & 0 & 60 & 40 & 0 & 20 & 60 & 20 \\
\hline
\end{tabular}

Tabel 3. Aktifitas belajar siswa (Nilai psikomotorik)

Berdasarkan data yang diperoleh dari hasil penelitian (Tabel 1) dapat diketahui bahwa aplikasi model pembelajaran kooperatif tipe TGT dapat meningkatkan motivasi dan hasil belajar siswa. Fakta tersebut menunjukkan adanya peningkatan pemahaman siswa terhadap materi yang dipelajari yaitu Animalia.

Hasil penelitian menunjukkan terjadinya perubahan tingkat belajar siswa di kelas. Adanya tindakan yang telah diberikan didukung dengan metode pembelajaran yang menarik telah memotivasi siswa untuk lebih semangat belajar. Siswa lebih mandiri dalam kegiatan pembelajaran dan mengerjakan soal post-test yang diberikan peneliti.

Penelitian dengan menggunakan metode TGT menunjukkan adanya peningkatan motivasi dan hasil belajar baik dari aspek kognitif maupun dari aspek afektif karena pembelajaran ini melibatkan seluruh siswa untuk aktif dalam mengikuti proses pembelajaran.

Penelitian ini merupakan hasil kolaborasi antara peneliti dengan guru bidang studi biologi dan kerjasama dengan seorang guru bidang studi fisika serta bimbingan dosen Biologi. Tindakan kelas dilaksanakan dengan tahapan melakukan survei dan observasi terlebih dahulu, kemudian membuat rencana tindakan dan melaksanakan tindakan yang berpedoman pada silabus dan rencana pembelajaran. Saat pelaksanaan tindakan, kolaborasi antara guru dengan peneliti sangat diperlukan. Dalam hal ini, peneliti berperan sebagai guru sekaligus observer, sedangkan guru lain yang terkait berperan sebagai observer yang mengamati kesibukan siswa selama pembelajaran dari aspek afektif. Selanjutnya hasil belajar yang telah dilakukan dapat direfleksikan dan dianalisis untuk mengetahui kebaikan dan kekurangannya sehingga pada pembelajaran selanjutnya diharapkan dapat lebih baik dan berkualitas.

Dalam pembelajaran siswa terlibat aktif melalui kegiatan membaca, berdiskusi, mengemukakan ide dan gagasan yang dilakukan secara berkelompok. Siswa membaca dengan tekun tentang pokok materi yang sedang dipelajari dan mendiskusikan materi dengan timnya sehingga setiap siswa memiliki kesempatan untuk mengemukakan ide maupun gagasannya. Kemudian saat game/turnamen berlangsung siswa memiliki kesempatan untuk menjawab pertanyaan, berlomba-lomba untuk meraih skor tertinggi sehingga mendapat penghargaan sebagai tim terbaik. Pada akhir tindakan diadakan pengisian angket motivasi dan post-test untuk mengetahui peningkatan motivasi dan kemampuan yang dicapai siswa pada aspek kognitif setelah pembelajaran.

Model pembelajaran kooperatif tipe TGT (Teams-Games-Tournament) dapat meningkatkan motivasi dan hasil belajar dikarenakan dalam pembelajaran TGT, siswa tidak hanya menerima apa yang diberikan oleh guru tetapi semua siswa turut berpartisipasi aktif dalam proses pembelajaran yaitu dengan diskusi dan permainan. Hal ini dapat meningkatkan minat dan motivasi siswa untuk mengikuti pembelajaran biologi. Siswa juga tidak merasa jenuh dan bosan karena dalam menyampaikan pembelajaran sikap guru tidak monoton namun ada variasi.

Selama pelaksanakan penelitian tindakan kelas yang dilakukan sebanyak dua siklus, terjadi peningkatan kualitas dalam pembelajaran. Hal ini dapat dilihat dari meningkatnya motivasi, hasil belajar siswa serta keaktifan siswa. Peningkatan kualitas pembelajaran terjadi secara bertahap pada setiap siklus yang pada akhirnya dapat meningkatkan hasil belajar.

Pada siklus I di awal pertemuan siswa terlihat antusias dalam mengikuti pembelajaran karena di awal sudah disampaikan metode pembelajaran yang akan di pakai. Nuansa serius karena akan presentasi dan perlombaan antar kelompok sehingga siswa serius menyimak penjelasan guru. Selain itu materi hewan avertebrata menarik karena mereka bisa mengetahui berbagai hewan yang selama ini belum jelas mereka ketahui, misalnya porivera, coelenterata, dan avertebrata yang lainnya. Pelaksanaan game/turnamen cukup efisien. Persiapan guru cukup matang dalam mengajar siswa dan saat mengerjakan post-test banyak siswa 
Jurnal Biologi dan Pembelajarannya, Vol 7 No 1, April 2020. Pp: 11-14

e-ISSN: $2406-8659$

memiliki rasa percaya diri yang bagus dalam mengerjakan soal karena menariknya hasil pembahasan materi. Nilai kognitif yang ditunjukkan siswa dengan nilai mencapai KKM pada siklus I yaitusejumlah 26 dari 34 siswa sedangkan pada siklus II sejumlah 29 dari 34 siswa. Hal ini menunjukkan bahwa hasil kognitif siswa mengalami peningkatan.

Sikap afektif yang paling tinggi adalah minat belajar yang mampu mencapai $80 \%$ baik pada siklus I, perhatian dan partisipasi mencapai $60 \%$ sangat baik pada siklus II, dan presentasi $60 \%$ baik pada siklus I. Secara umum hasinya adalah baik dan sangat baik ketika di terapkan model belajar TGT.

Tingginya nilai rata-rata pada metode pembelajaran TGT disebabkan karena pada proses pembelajaran siswa tidak lagi dijadikan sebagai objek melainkan siswa terlibat secara aktif dalam proses pembelajaran. Dari proses pembelajaran tersebut siswa mendapatkan pengalaman belajar sesuai dengan kajian ilmu pengetahuan yang dipelajarinya secara optimal. Pada pembelajaran TGT, siswa dilatih dan dituntut agar dapat bekerja sama, tidak malu untuk berbicara tentang materi yang belum dipahami dan dikuasai, saling meningkatkan keterampilan dalam berkomunikasi sehingga tidak terjadi kesalahpahaman dan meningkatkan aktivitas dan kreativitas siswa. Ini sesuai dengan yang dikemukakan oleh Melvin L. Silberman (2007), yaitu ketika pembelajaran itu aktif apabila siswa melakukan aktivitas, mereka menggunakan potensi otak untuk mengkaji ide-ide, memecahkan masalah dan menerapkan apa yang mereka pelajari.Moh. Uzer Usman (2005), menyatakan bahwa dalam menciptakan kondisi pembelajaran yang efektif, guru harus: 1) melibatkan siswa secara aktif; 2) menarik minat dan perhatian siswa; 3) membangkitkan motivasi siswa; dan 4) memperhatikan perbedaan individu siswa.

Berdasarkan hasil yang telah dicapai selama pelaksanaan pembelajaran dengan mengaplikasikan metode TGT, siswa mengalami peningkatan baik dari segi motivasi, aspek kognitif maupun afektif. Pada setiap siklus terjadi peningkatan hasil belajar. Berdasarkan hasil yang diperoleh maka uraian teori yang terdapat dalam bab II mendukung

\section{SIMPULAN}

Berdasarkan hasil pengamatan dan tindakan perbaikan pembelajaran yang telah dilaksanakan, dapat diambil kesimpulan bahwa:Penerapan model pembelajaran kooperatif team games tournament (TGT) dapat meningkatkanmotivasi belajar siswa pada pelajaran biologi kelasa X SMA bina insan mandiri materi Animalia yang di lihat dari meningkatnya motivasi belajar siswa yang memiliki motivasi tinggi dari $38,6 \%$ menjadi $61,4 \%$; serta mampu meningkatkan hasil belajar siswa dilihat dari peningkatan jumlah siswa dengan nilai tuntas pada siklus I dan llyang mengalami kenaikan dari 26 siswa $(76,5 \%)$ menjadi 32 siswa $(85,2 \%)$.

\section{SARAN}

\section{UCAPAN TERIMA KASIH}

\section{DAFTAR PUSTAKA}

[1] Suryosubroto B, 2009. Proses Belajar Mengajar Sekolah Wawasan Baru. Jakarta : Rineka Cipta

[2] Hisyam Zaini, 2004. Strategi Pembelajaran Aktif. Yogyakarta: IAIN Sunan Kalijogo

[3] Nurholis, 2013. Kelebihan dan Kekurangan TGT (di akses pada: nurholis-home edukasi. Blogspot.com)

[4] Siberman, Melvin L, 2007. Strategi Pembelajaran Aktif. Yogyakarta

[5] Moh. Uzer Usman, 2005. Menjadi Guru Profesional Bandung: Remaja Rosdakarya 